Revta brasil. Bot., São Paulo, V.24, n.3, p.295-301, set. 2001

\title{
Variações diurnas da atividade in vivo da redutase do nitrato em abacaxizeiro (Ananas comosus (L.) Merr. - Bromeliaceae)
}

\author{
CATARINA CARVALHO NIEVOLA ${ }^{1}$ e HELENICE MERCIER ${ }^{1,2}$
}

(recebido: 19 de outubro de 2000; aceito: 6 de junho de 2001)

\begin{abstract}
Diurnal rhythm of in vivo activity of nitrate reductase in pineapple (Ananas comosus (L.) Merr. - Bromeliaceae). Determination of nitrate reductase activity (NR) was based on the in vivo assay method, which was standardised for leaves and roots of pineapple cultivated in vitro. The highest activity was obtained when tissues were incubated in $0.1 \mathrm{M}$ phosphate buffer, $100 \mathrm{mM} \mathrm{KNO}$ and $3 \%$ of n-propanol. The optimal $\mathrm{pH}$ ranged from 6.5 to 7.5. The incubation period was $60 \mathrm{~min}$ at $30{ }^{\circ} \mathrm{C}$. This standardisation was important for the diurnal rhythm analysis of nitrate reductase activity in pineapple because the conditions of in vivo assay for this enzyme vary significantly among different plant species. The diurnal rhythm analysis showed that in leaves, the highest activity occurred during the day. The NR activity in the roots during the dark period was similar to that observed during the light period. The NR activity in roots was always higher than in leaves, indicating that roots are an important site for nitrate reduction when pineapple is cultivated in vitro. The nitrate accumulation in leaves during the diurnal cycle showed that it is present in higher concentrations in the light period. Therefore a positive correlation between nitrate concentration and NR activity could be established. In roots, however, the highest nitrate concentrations were observed in the absence of light. In this case, it is possible that other factors, besides nitrate, contributed to a higher enzymatic activity during the light period.
\end{abstract}

RESUMO - (Variações diurnas da atividade in vivo da redutase do nitrato em abacaxizeiro (Ananas comosus (L.) Merr. Bromeliaceae). A análise da atividade enzimática da redutase do nitrato baseou-se no método do ensaio in vivo, que foi padronizado para os tecidos foliares e radiculares do abacaxizeiro cultivado in vitro. As maiores atividades enzimáticas foram obtidas quando se empregou como meio de reação uma solução tampão fosfato $0,1 \mathrm{M}$, contendo $\mathrm{KNO}_{3} 100 \mathrm{mM}$ e $3 \%$ de $\mathrm{n}$ propanol, a faixa de $\mathrm{pH}$ ótimo foi de 6,5 a 7,5 . O tempo de incubação foi de $60 \mathrm{~min}$ a $30^{\circ} \mathrm{C}$. Essa padronização mostrou-se muito importante para a análise do ritmo diurno da redutase do nitrato em abacaxizeiro, visto que as condições de ensaio in vivo dessa enzima variam muito entre diferentes espécies vegetais. As folhas apresentaram as maiores atividades na presença de luz. As raízes mostraram atividade da redutase do nitrato também na ausência de luminosidade em níveis semelhantes aos observados na presença de luz. A atividade observada nas raízes foi sempre superior à das folhas, sugerindo que as raízes têm um importante papel na redução do nitrato nas condições de cultivo in vitro. O acúmulo de nitrato observado durante o ciclo diurno, nas folhas, evidenciou que a presença desse íon ocorreu em maiores níveis durante o período luminoso, estabelecendo uma correlação positiva com a atividade da redutase do nitrato. Entretanto, nas raízes, as maiores concentrações foram observadas na ausência de luz. Nesse caso, discute-se a possibilidade de outros fatores, além do nitrato, estarem contribuindo positivamente, induzindo uma elevada atividade enzimática na presença de luz.

Key words - Nitrate reductase, pineapple, diurnal rhythm, bromeliad, Bromeliaceae

\section{Introdução}

Ao longo da evolução, as plantas desenvolveram vários mecanismos para a utilização de diferentes formas de nitrogênio. O nitrato é considerado uma das fontes nitrogenadas mais importantes para os vegetais (Crawford 1995). Entretanto, esse íon deve ser reduzido a amônio antes de ser incorporado em aminoácidos e outras moléculas orgânicas. O processo de redução do nitrato é constituído de duas

1. Universidade de São Paulo, Instituto de Biociências, Laboratório de Fisiologia Vegetal, Caixa Postal 11461, 05422-970 São Paulo, SP, Brasil.

2. Autor para correspondência: hmercier@usp.br etapas catalisadas pelas enzimas redutase do nitrato $(\mathrm{RN})$ e redutase do nitrito $(\mathrm{RNi})$ (Kleinhofs \& Warner 1990), sendo a primeira delas considerada a enzimachave na assimilação do nitrato.

O ensaio in vivo de determinação da atividade da $\mathrm{RN}$ tem sido amplamente utilizado como indicador do metabolismo do nitrogênio nos vegetais. Muitos autores consideram essa metodologia como a mais adequada para a comparação da atividade da RN entre espécies diferentes ou entre tratamentos distintos (Crafts-Brandner \& Harper 1982, Singh 1994, Cairo et al. 1994). O método in vivo, descrito por Jaworski (1971), consiste na incubação do tecido vegetal em meio apropriado de ensaio, em condições de obscuridade, sendo a taxa de difusão do nitrito para a solução de incubação utilizada como indicadora da 
atividade da enzima. Esse sistema de análise pressupõe que haja uma absorção prévia do nitrato pelo tecido, que exista uma concentração endógena de NADH e que ocorra a subseqüente liberação do nitrito formado para o meio de reação. Ele é considerado um método simples e rápido, porém, vários fatores relacionados com as condições de ensaio podem interferir na expressão da atividade enzimática tais como: a concentração exógena de nitrato, o $\mathrm{pH}$, a temperatura de incubação e o emprego de substâncias que alteram a permeabilidade da membrana celular (Lee \& Titus 1992). Além disso, um outro fator deve ser considerado: o ritmo diurno de atividade da $\mathrm{RN}$, já observado em várias plantas (Hoff et al.1992). O conhecimento da variação da atividade da RN no ciclo diurno é extremamente importante para se determinar o horário ideal para a realização do ensaio, fazendo coincidir com o período correspondente à máxima atividade da $\mathrm{RN}$.

O abacaxizeiro é uma bromélia terrestre de expressiva importância econômica (Cunha et al. 1994). Apesar da relevância dessa cultura, inexistem estudos específicos de padronização das condições de ensaio in vivo para $\mathrm{RN}$, além de não ser conhecido o ritmo diurno dessa enzima para essa bromélia. Assim, para que os estudos de metabolismo do nitrogênio em bromeliáceas possam avançar adequadamente, é preciso que conhecimentos básicos sejam gerados, permitindo, por exemplo, a aplicação apropriada de metodologias conhecidas, mas que foram padronizadas para outras plantas, como a macieira (Lee \& Titus 1992), a soja (Crafts-Brandner \& Harper 1982), o cafeeiro (Queiroz et al. 1991) e para as plantas de trigo (Brunetti \& Hageman 1976), aveia e cevada (Lillo \& Herniksen 1984).

O presente trabalho teve como objetivos adequar a metodologia do ensaio in vivo de avaliação da atividade da $\mathrm{RN}$ para folhas e raízes do abacaxizeiro (Ananas comosus L. Merr.), e investigar a atividade diurna dessa enzima, correlacionando com os níveis endógenos de nitrato.

\section{Material e Métodos}

As plantas de Ananas comosus (L. Merr.) foram obtidas a partir da micropropagação, utilizando segmentos nodais (Kiss et al. 1995) provenientes de um clone existente no Laboratório de Fisiologia Vegetal do IBUSP. O meio de cultura empregado foi o de Murashigue \& Skoog (MS) (1962), pH 5,8 , acrescido de ágar na concentração de 6 g..$^{-1}$, sacarose $3 \%$ e $0,1 \mathrm{mg} .1^{-1}$ de tiamina. Esses segmentos caulinares foram inoculados em frascos tipo Erlenmayer de capacidade para $125 \mathrm{ml}$, contendo $50 \mathrm{ml}$ de meio MS cada um deles. Os frascos foram mantidos em câmaras de incubação do tipo BOD em fotoperíodo de 16 horas. O tempo de cultivo foi de três meses, possibilitando, assim, a obtenção de plantas (eixo caulinar e raízes) de aproximadamente $4 \mathrm{~cm}$ de altura. Após esse período, elas foram destinadas aos ensaios enzimáticos e à determinação do nitrato endógeno.

Para as análises da atividade da $\mathrm{RN}$ empregou-se o método in vivo descrito por Jaworski (1971). As plantas ao serem retiradas dos frascos de cultura foram lavadas com água destilada. Em seguida, as folhas e raízes foram fragmentadas em pequenos segmentos (cerca de $200 \mathrm{mg}$ de folhas e $50 \mathrm{mg}$ de raízes). Esses materiais isoladamente foram depositados em tubos de ensaio, onde se adicionaram $6 \mathrm{ml}$ de uma solução de incubação. Esta foi constituída por tampão fosfato $0,1 \mathrm{M}$, contendo n-propanol e $\mathrm{KNO}_{3}$ (substrato da $\mathrm{RN}$ ). Esses dois últimos componentes tiveram suas concentrações analisadas. Antes de se iniciar cada experimento, a solução de incubação foi submetida a uma desgaseificação em sonicador. $\mathrm{O}$ tecido vegetal, submerso nessa solução, foi infiltrado à vácuo por três vezes de $1 \mathrm{~min}$. Após esse procedimento, os frascos foram mantidos, na ausência de luz, em banho-maria a $30^{\circ} \mathrm{C}$. Foram avaliados os efeitos da variação da concentração de $\mathrm{KNO}_{3}$, do tempo de incubação, do $\mathrm{pH}$, da temperatura e da concentração de n-propanol no meio de incubação. Primeiramente, sob $30{ }^{\circ} \mathrm{C}$ e pH 7,5 e com tempo de reação de $60 \mathrm{~min}$, as concentrações de $\mathrm{KNO}_{3}$ testadas variaram de $0,25,50,100$ a $150 \mathrm{mM}$. Após conhecer a concentração ideal do substrato da enzima, variou-se o tempo de reação, retirando-se amostras do meio de incubação aos $0,5,15,30,60,90$ e 120 min de permanência dos tecidos na solução mantida a $30^{\circ} \mathrm{C}$. Em seguida, foram testados os seguintes valores de $\mathrm{pH}$ do meio de incubação: $6 ; 6,5 ; 7 ; 7,5 ; 8 ; 8,5$ e 9. Definido o pH ótimo, o meio de incubação foi submetido às temperaturas de 20,25 , $30,35,40$ e $45^{\circ} \mathrm{C}$. Posteriormente, foram avaliadas as concentrações de n-propanol $(0,1,2,3,4$ e 5\%), otimizando a liberação de nitrito para o meio de incubação.

Para se determinar a quantidade de nitrito formada pela reação, cada alíquota de $1 \mathrm{ml}$ retirada do meio de incubação foi adicionada de $0,3 \mathrm{ml}$ de sulfanilamida $1 \% \mathrm{em} \mathrm{HCl} 3 \mathrm{M}$ e de mais $0,3 \mathrm{ml}$ de $\mathrm{N}$-naftil-etileno-diamino a $0,02 \%$, completando-se o volume final para $2,5 \mathrm{ml}$ com água ultrafiltrada. As leituras foram feitas em espectrofotômetro a $540 \mathrm{~nm}$. A atividade da enzima foi expressa em nmoles de $\mathrm{NO}_{2}^{-}$liberados pelo tecido vegetal na solução de incubação por hora, por grama de matéria fresca (nmoles de $\mathrm{NO}_{2}^{-} \cdot \mathrm{h}^{-1} \cdot \mathrm{g} \mathrm{mf}^{-1}$ ).

$\mathrm{O}$ teor de nitrato foi determinado pelo método descrito por Cataldo et al. (1975). A extração foi feita a partir de tecidos congelados das folhas e raízes do abacaxizeiro. Cerca de $1 \mathrm{~g}$ de folhas e $0,1 \mathrm{~g}$ de raízes foram macerados em almofariz com $5 \mathrm{ml}$ de água ultrafiltrada em temperatura ambiente. Após a homogeneização, esses materiais foram submetidos a uma centrifugação de $15.000 \mathrm{rpm}$ por $30 \mathrm{~min}$, coletando-se o sobrenadante e centrifugando-o por mais $15 \mathrm{~min}$ a $15.000 \mathrm{rpm}$. O sobrenadante seguinte foi utilizado para as análises de nitrato. A cada alíquota de $200 \mu \mathrm{l}$ foram adicionados $800 \mu \mathrm{l}$ de ácido salicílico $5 \%$ em ácido sulfúrico concentrado. Após um período de $20 \mathrm{~min}$ à temperatura ambiente, foram adicionados $19 \mathrm{ml}$ de $\mathrm{NaOH} 2 \mathrm{~N}$, elevando o pH acima de 12. A absorbância da mistura resultante foi analisada a $410 \mathrm{~nm}$. 
Nos experimentos relacionados à padronização do ensaio enzimático, a coleta ocorreu no período que correspondeu a $3 \mathrm{~h}$ após o início do período luminoso. O ensaio de determinação da atividade da $\mathrm{RN}$ e da quantidade de nitrato endógeno durante o ciclo diurno incluiu amostras coletadas em intervalos de $2 \mathrm{~h}$ no decorrer de $24 \mathrm{~h}$.

Os experimentos foram realizados em triplicatas, sendo que em cada repetição foram utilizadas cerca de 100 plantas. Os resultados foram apresentados na forma de gráficos. A representação dos desvios padrões das médias foi sempre menor que os símbolos utilizados para caracterizar as atividades enzimáticas e determinação de nitrato nos materiais analisados (folhas e raízes).

\section{Resultados e Discussão}

A metodologia in vivo de análise da atividade da $\mathrm{RN}$ oferece uma estimativa satisfatória da redução do íon nitrato in situ, possibilitando a quantificação do nitrito produzido por células intactas de pequenos segmentos de tecidos vegetais (Hageman \& Reed 1980).

A padronização do ensaio in vivo da $\mathrm{RN}$ para abacaxizeiro foi feita visando adequar a concentração de substrato, o tempo de incubação, o pH, a temperatura e por fim, a concentração de n-propanol. Os dados da figura 1A mostram a relação existente entre a atividade da $\mathrm{RN}$ e a concentração do substrato enzimático no meio de incubação. A partir de $25 \mathrm{mM}$ observou-se um aumento na atividade da enzima, atingindo um valor máximo a partir de $50 \mathrm{mM}$. Devido à pequena diferença na atividade da $\mathrm{RN}$ verificada entre $50 \mathrm{mM}$ e $100 \mathrm{mM}$, foi escolhida a concentração de $100 \mathrm{mM}$ de nitrato como a mais adequada tanto para as folhas como para as raízes. Tal escolha se deveu ao fato de que a atividade detectada na concentração de $50 \mathrm{mM}$ encontrar-se no limiar, no qual pequenas reduções na concentração do substrato poderiam induzir a redução na assimilação do nitrato. $\mathrm{O}$ aumento da atividade da $\mathrm{RN}$ em resposta ao incremento de substrato tem sido associado à síntese "de novo" da proteína, bem como à sua ativação (Solomonson \& Barber 1990). Em relação às raízes, foi detectada uma atividade enzimática substancial mesmo quando não foi adicionado o substrato da enzima ao meio de incubação (nitrato). Essa observação indica que as raízes do abacaxizeiro seriam armazenadoras de nitrato, pois, nesse caso, foi o nitrato endógeno que induziu a atividade da NR. Nesse caso, é possível que tenha havido, preferencialmente, a reativação da enzima à semelhança do que ocorreu com a espécie arbórea Hovenia dulcis (Cairo et al. 1994).
Em relação à produção de nitrito em função do tempo de reação (figura 1B), evidenciou-se uma relação linear nos tempos de 30 a $60 \mathrm{~min}$, coincidindo com um grande aumento da atividade de $\mathrm{RN}$ em ambos os tecidos (os valores de inclinação da reta foram maiores na faixa de 30 a 60 min em relação aos intervalos de tempo inferiores a $30 \mathrm{~min}$ ). A utilização desse intervalo de tempo segue, também, a recomendação de não se ultrapassar o período de uma hora em ensaios in vivo, evitando, assim, alterações metabólicas no tecido (L'vov \& Safaraliev 1988).

A figura $1 \mathrm{C}$ mostra a relação entre a atividade da $\mathrm{RN}$ e o pH do meio de reação. As maiores atividades foram observadas na faixa de $\mathrm{pH}$ entre 6,5 e 7,5 tanto para as folhas quanto para as raízes. Esses resultados favorecem o ensaio in vivo da enzima, já que possibilita o emprego de uma faixa relativamente ampla de pH. Para os demais experimentos utilizou-se, então, o pH 7,5. A otimização da atividade da $\mathrm{RN}$ em um pH próximo ao da neutralidade tem sido demonstrada para várias plantas, como as de trigo (Brunetti \& Hageman 1976), as de soja (Crafts-Brandner \& Harper 1982), as de cevada (Lillo 1983) e as de macieira (Lee \& Titus 1992), dentre outras.

Como apresentado na figura $1 \mathrm{D}$, a faixa de temperatura que possibilitou a maior atividade da RN está situada entre 30 e $35^{\circ} \mathrm{C}$. Temperaturas inferiores ou superiores a esses valores causaram um declínio na atividade tanto de folhas quanto de raízes. A queda na atividade enzimática sob temperaturas elevadas, a partir de $45^{\circ} \mathrm{C}$ poderia estar associada à termodesnaturação protéica da enzima, refletindo na diminuição da redução do nitrato.

De acordo com a figura $1 \mathrm{E}$, observa-se que a utilização de 3\% de n-propanol para as raízes e 4\% para as folhas, maximizaram a atividade da RN. O efeito estimulatório do n-propanol na atividade da $\mathrm{RN}$ tem sido atribuído ao fato de que esse reagente aumentaria a permeabilidade celular ao nitrato e nitrito (Jaworski 1971). Assim, o n-propanol poderia estar facilitando a transferência do nitrato presente no meio de incubação, ou oriundo do vacúolo, em direção ao citoplasma, onde estaria mais acessível à redução pela RN. Além disso, facilitaria a liberação do nitrito produzido na célula para a solução de incubação (Jones \& Sheard 1977).

Em resumo, para o abacaxizeiro, a padronização das condições mais favoráveis ao ensaio in vivo da $\mathrm{RN}$ foi: $100 \mathrm{mM}$ de nitrato, $3 \%$ e $4 \%$ de n-propanol, pH 7,5 e tempo de incubação de 60 min. É interessante 

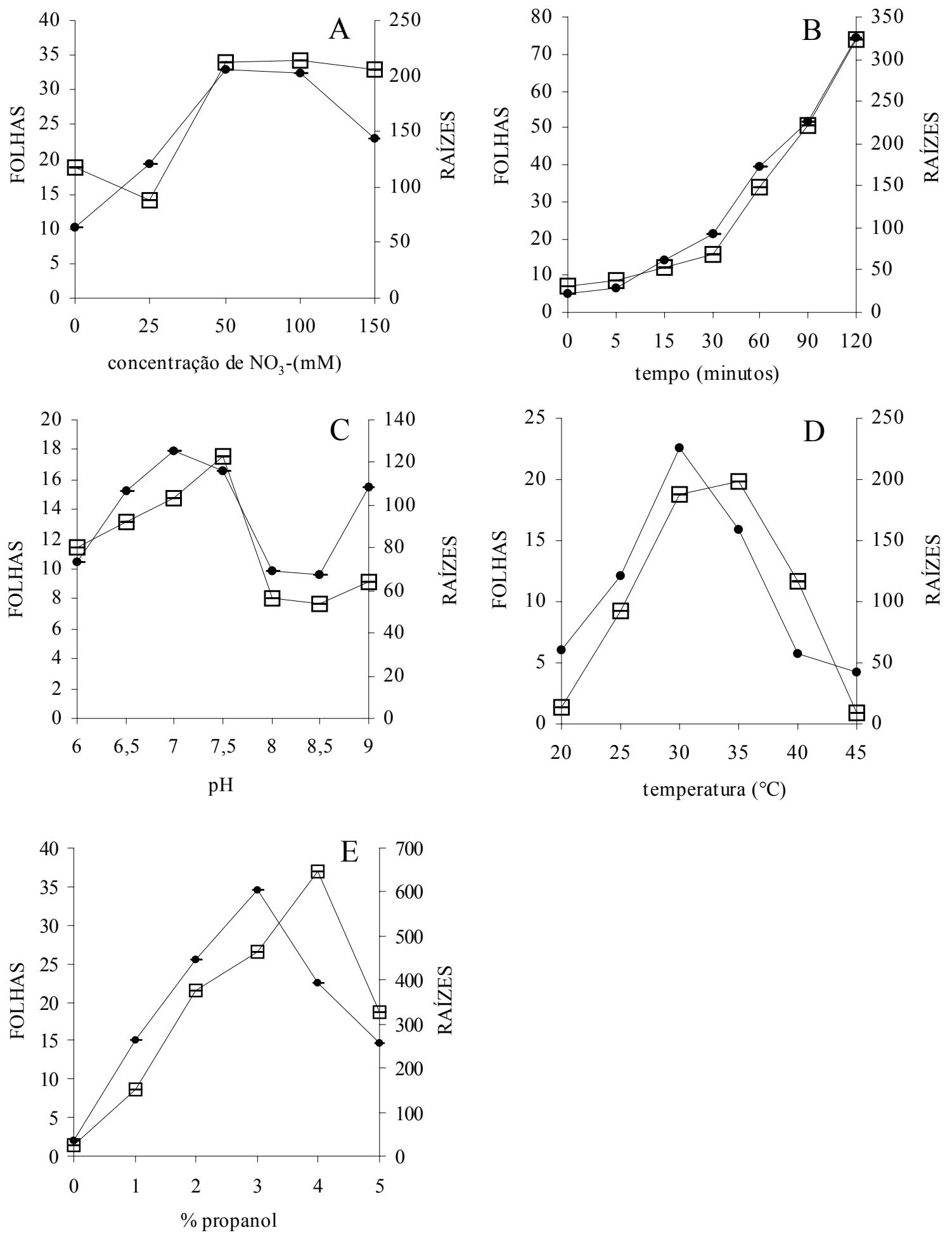

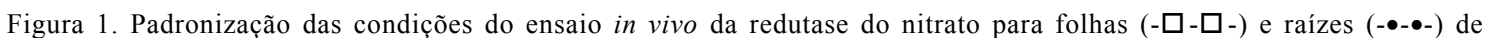
abacaxizeiro. A. concentração de $\mathrm{NO}_{3}^{-}$, B. tempo de incubação; C. pH, D. temperatura, E. concentração de n-propanol. A atividade enzimática foi expressa em nmoles $\mathrm{NO}_{2}^{-} \cdot \mathrm{h}^{-1} \cdot \mathrm{g} \mathrm{mf}{ }^{-1}$. 
constatar que esses parâmetros variam de espécie para espécie, como por exemplo para a macieira, cuja concentração ótima de nitrato na solução de incubação foi de $50 \mathrm{mM}$, contendo $2 \%$ de n-propanol (Lee \& Titus 1992). No caso do algodoeiro, a melhor concentração de nitrato foi de $30 \mathrm{mM}$ e $1 \%$ de npropanol (Radin 1973). Já para plantas de milho, o ensaio in vivo da $\mathrm{RN}$ foi realizado com $0,1 \mathrm{M}$ de $\mathrm{KNO}_{3}$ e 1\% de n-propanol (Machado et al. 1998). Espécies arbóreas apresentaram maior atividade da NR quando a concentração de n-propanol atingiu 5\%, sendo que a quantidade de nitrato pôde variar entre $25 \mathrm{mM}$ e 100 mM (Cairo et al. 1994). Em relação à temperatura, embora a maioria das espécies estudadas apresente maior atividade da $\mathrm{RN}$ in vivo a $30^{\circ} \mathrm{C}$, foi demonstrado por Singh (1994) que a máxima atividade dessa enzima em Crotalaria juncea foi alcançada em $40^{\circ} \mathrm{C}$. Assim, verifica-se que as condições para a realização do ensaio in vivo podem variar muito, tornando a padronização para cada espécie um pré-requisito importante à determinação da atividade da RN.

Em relação à caracterização da atividade da $\mathrm{RN}$ durante o ciclo diurno do abacaxizeiro, observou-se que para as folhas, o período de maior atividade ocorreu durante a presença de luz (figura 2). Já as raízes, além de apresentarem atividade na presença de luz, também mostraram atividade significativa durante sua ausência ( $2 \mathrm{~h}$ antes do período luminoso).

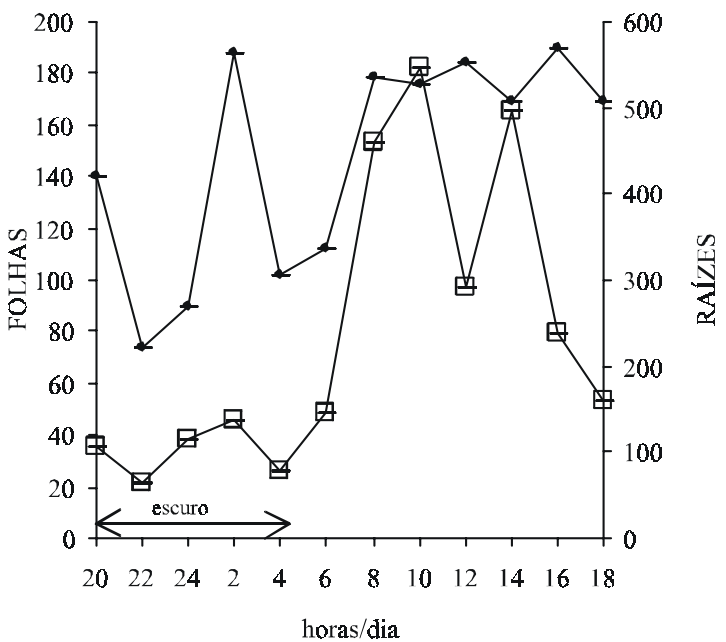

Figura 2. Atividade in vivo da redutase do nitrato durante o

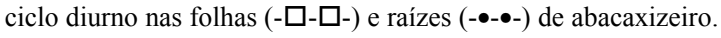
$\mathrm{A}$ atividade enzimática foi expressa em nmoles $\mathrm{NO}_{2} \cdot \mathrm{h}^{-1} \cdot \mathrm{g} \mathrm{mf}$ 1 .
A atividade da $\mathrm{RN}$ correspondente à parte radicular atingiu níveis sempre superiores aos das folhas (aproximadamente três vezes). Isto sugere que a raiz foi o principal órgão de redução do nitrato na condição de cultivo in vitro. Tachibana et al. (1991) também observaram que tanto o nível de atividade da $\mathrm{RN}$ quanto o ritmo podem variar entre as raízes e as folhas de plantas de pepino. O efeito da luz tem sempre sido um fator importante na compreensão do ritmo diurno da RN. Experimentos realizados por Galangau et al. (1988), utilizando plantas de tomate, evidenciaram que a expressão dos genes da $\mathrm{RN}$ exibiu um ciclo no qual a transcrição do RNAm aumentou, consideravelmente, antes do amanhecer, decrescendo durante as horas subseqüentes até tornar-se indetectável no final da tarde.

Paralelamente, esses mesmos pesquisadores analisaram a quantidade de proteína, além da atividade da $\mathrm{RN}$, durante o ciclo diurno. A máxima atividade de $\mathrm{RN}$ detectada ocorreu $2 \mathrm{~h}$ após o início da luz, ou seja, correspondendo a $2 \mathrm{~h}$ após o pico do aparecimento da proteína RN. Assim, foi sugerido que a luz estaria envolvida na regulação da expressão dos genes da RN. Lillo (1991) demonstrou que pode haver também um controle pós-traducional da atividade da RN relacionado ao ritmo diurno da RN em plantas de milho. Posteriormente, Lillo (1994) verificou, também, que a glicose ou a sacarose poderia

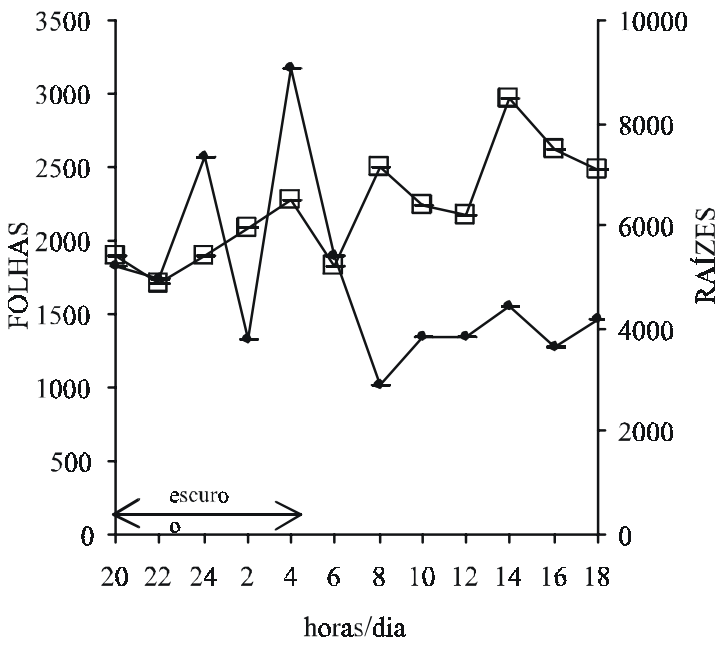

Figura 3. Nitrato endógeno durante o ciclo diurno nas folhas

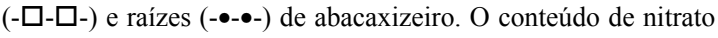
foi expresso em mmoles $\mathrm{NO}_{3}{ }^{-} \cdot \mathrm{g} \mathrm{mf} \mathrm{m}^{-1}$. 
substituir a luz na indução do acúmulo de RNAm da $\mathrm{RN}$, sugerindo que os esqueletos carbônicos seriam os fatores determinantes da atividade da RN. Um outro fator decisivo para propiciar a redução do nitrato é a quantidade de NADH disponível. Este seria produzido via oxidação do malato durante a ausência ou na presença de luz (Naik \& Nicholas 1986, Weger \& Turpin 1989). Entretanto, na ausência de luz, os níveis de atividade encontrados são, na quase totalidade dos casos, inferiores aos observados no período de luminosidade. Ressalta-se, assim, a importância dos resultados de assimilação do nitrogênio em $A$. comosus ora apresentados, já que é bastante incomum o relato da existência de níveis elevados de atividade da RN durante a ausência de luz.

A disponibilidade de nitrato pode interferir positivamente no aumento da atividade da $\mathrm{RN}$, pois trata-se do substrato da enzima (Crawford 1995, Tachibana et al. 1991). A análise do conteúdo endógeno de nitrato no abacaxizeiro (figura 3) evidenciou que os maiores teores foliares ocorreram durante o período luminoso, podendo ser correlacionados com as maiores atividades da $\mathrm{RN}$ (figura 2). Nas raízes, ao contrário, os maiores níveis de nitrato foram observados durante a ausência de luz (figura 3). Porém, durante o período de luminosidade os níveis de nitrato nas raízes diminuíram, ao passo que os níveis de atividade da RN mantiveram-se elevados. Nesse caso, é provável que outros fatores possam estar interferindo positivamente, como por exemplo a disponibilidade maior de NADH citossólico na presença de luz. Segundo Kaiser et al. (2000), a redução do nitrato in situ é limitada principalmente pela disponibilidade de NADH citossólico. É interessante ressaltar que para o abacaxizeiro, o nível de nitrato endógeno das raízes durante o ciclo diurno foi sempre superior ao observado nas folhas (figura 3), o que mostra ser esse órgão importante local armazenador de nitrato nas condições de cultivo in vitro.

Agradecimentos - As autoras agradecem à CAPES pela bolsa concedida à C.C. Nievola e à FAPESP pelo suporte financeiro ao projeto (99/02660-9).

\section{Referências bibliográficas}

BRUNETTI, N. \& HAGEMAN, R.H. 1976. Comparison of in vivo and in vitro assays of nitrate reductase in wheat (Triticum aestivum L.) seedlings. Plant Physiology 58:583-587.
CAIRO, P.A.R., OLIVEIRA, L.E.M. \& DELÚ FILHO, N. 1994. Determinação das condições ótimas para o ensaio in vitro da redutase do nitrato em algumas espécies arbóreas. Revista Árvore 18:87-95.

CATALDO, D.A., HAROON, M., SCHRADER, L.E. \& YOUNGS, V.L. 1975. Rapid colorimetric determination of nitrate in plant tissue by nitration of salicylic acid. Communications of Soil Science and Plant Annals 6:7180.

CRAFTS-BRANDNER, S.J. \& HARPER, J.E. 1982. Nitrate reduction by roots of soybean (Glycine $\max$ [L.] Merr.) seedlings. Plant Physiology 69:1928-1303.

CRAWFORD, N.M. 1995. Nitrate: nutrient and signal for plant growth. The Plant Cell 7:859-868.

CUNHA, G.A.P., MATOS, A.P., CABRAL, J.R.S., SOUZA, L.F.S., SANCHES, N.F. \& REINHARDT, D.H.R.C. 1994. Abacaxi para exportação: aspectos técnicos da produção. Frupex. Ministério da Agricultura, do Abastecimento e da Reforma Agrária. Secretaria do Desenvolvimento Rural, Brasília.

GALANGAU, F., DANIEL-VEDELE, F., MOUREAUX, T. DORBE, M., LEYDECKER, M.T. \& CABOCHE, M. 1988. Expression of leaf nitrate reductase genes from tomato and tobacco in relation to light-dark regimes and nitrate supply. Plant Physiology 88:383-388.

HAGEMAN, R. \& REED, A.J. 1980. Nitrate reductase from higher plants. In Methods in Enzymology (M.P. Deutscher, ed.). Academic Press Inc., San Diego. v.69, p. 270-280.

HOFF, T., STUMMANN, M. \& HENNINGSENM, K.W. 1992. Structure, function and regulation of nitrate reductase in higher plants. Physiologia Plantarum 84:616-624.

JAWORSKI, E.G. 1971. Nitrate reductase assay in intact plant tissues. Biochemical and Biophysical Research Communications 43:1274- 1279.

JONES, R.W. \& SHEARD, R.W. 1977. Conditions affecting in vivo nitrate reductase activity in chlorophyllous tissues. Canadian Journal of Botany 55:896-901.

KAISER,W.M., KANDLBINDER, A., STOIMENOVA, M. \& GLAAB, J. 2000. Discrepancy between nitrate reduction rates in intact leaves and nitrate reductase activity in leaf extracts: What limits nitrate reduction in situ. Planta 210:801-807.

KISS, E., KISS, J., GYULAI, G. \& HESZKY, L.E. 1995. A novel method for rapid micropropagation of pineaple. Hortscience 30:127-129.

KLEINHOFS, A. \& WARNER, R.L. 1990. Advances in nitrate assimilation. In The Biochemistry of plants (B.J. Miflin \& P.J. Stewart, eds.). Academic Press Inc., London, v.16, p. $89-120$.

L'VOV, N.P. \& SAFARALIEV, P.M. 1988. Methods of determining nitrate reductase activity in plants. Methods 35:196-200.

LEE, H.J. \& TITUS, J.S. 1992. Factors affecting the in vivo nitrate reductase assay form MM106 apple trees. Communications Soil Science and Plant Analysis 23:981991.

LILLO, C. \& HERNIKSEN, A. 1984. Comparative studies of diurnal variations of nitrate reductase activity in wheat, oat and barley. Physiologia Plantarum 62:89-94. 
LILLO, C. 1983. Studies of diurnal variations of nitrate reductase activity in barley leaves using various assay methods. Physiologia Plantarum 57:357-362.

LILLO, C. 1991. Diurnal variations of corn leaf nitrate reductase: an experimental distinction between transcriptional and post-transcriptional control. Plant Science 73:149-154.

LILLO, C. 1994. Light regulation of nitrate reductase in green leaves of higher plants. Physiologia Plantarum 90:616-620.

MACHADO, A.T., SODEK, L., DÖBEREINER, J. \& REIS, V.M. 1998. Efeito da adubação nitrogenada e da inoculação com bactérias diazotróficas no comportamento bioquímico da cultivar de milho nitroflint. Pesquisa Agropecuária Brasileira 33:961-970.

MURASHIGE, T. \& SKOOG, F. 1962. A revised medium for rapid growth and bioassays with tobacco tissue cultures. Physiologia Plantarum 15:473-497.

NAIK, M.S. \& NICHOLAS, D.J.D. 1986. Malate metabolism and its relation to nitrate assimilation in plants. Phytochemistry 25:571-576.
QUEIROZ, C.G.S., ALVES, J.D., RENA, A.B. \& CORDEIRO, A.T. 1991. Efeito do cloranfenicol, n-propanol, pH e temperatura sobre a atividade in vivo da redutase do nitrato em cafeeiros jovens. Revista Brasileira de Botânica 14:7377.

RADIN, J.W. 1973. In vivo assay of nitrate reductase in cotton leaf discs. Plant Physiology 51:332-336.

SINGH, V.K. 1994. Optimum conditions for measurement of nitrate reductase activity in the leaves of blast fibre yielding plants. Proceedings Natural Academic Science India 64:389-398.

TACHIBANA, S., KONISHI, N. \& KANDA, H. 1991. Diurnal variation of in vivo nitrate reductase activity in cucumber plants. Journal Japan Social Horticulture Science 60:593599.

SOLOMONSON, L.P. \& BARBER, M.J. 1990. Assimilatory nitrate reductase: functional properties and regulation. Annual Review Plant Physiology Plant Molecular Biology 41:225-253.

WEGER, H.G. \& TURPIN, D.H. 1989. Mitochondrial respiration can support $\mathrm{NO}_{3}^{-}$and $\mathrm{NO}_{2}^{-}$reduction during photosynthesis. Plant Physiology 89:409-415. 
